\title{
DENTAL AND FACIAL INJURIES IN INTERNATIONAL FIELD HOCKEY
}

\author{
J. H. A. BOLHUIS, J. M. M. LEURS and G. E. FLÖGEL*
}

Department of Maxillo-Facial Prosthetics and *Department of Prosthetic Dentistry, State University of Utrecht, The Netherlands

\section{ABSTRACT}

In many respects international sportsmen are trendsetters for the behaviour of recreational sportsmen. For this reason the attitude of international hockey players towards mouth protectors was studied. The possession and use of mouth protectors vary markedly between different countries. The incidence of dental-facial traumas among international field hockey players is high; $54 \%$ had sustained injuries necessitating a visit to a physician and/or a dentist. Of these victims $20 \%$ sustained serious dental damage at least once (women $16 \%$ and men $22 \%$ ). Only $20 \%$ of the international players wear a mouth protector consistently during training and matches. Women use the apparatus almost twice as much as men. The main argument in rejecting a mouth protector is that it is not felt to be necessary.

Keywords: Prevention, Mouth protectors

\section{INTRODUCTION}

Field hockey accounts for a large number of dental injuries every year (Bolhuis et al, 1986). The damage is mostly severe and, in contrast to other physical damage, mostly irreversible. Most dental traumas do not heal; they can only be repaired and even the best repair has a limited lifetime. Mouth protectors are effective in preventing these traumas (Garon et al, 1986; Wijn et al, 1986 and in reports by the Bureau of Health Education, 1984 and the Bureau of Dental Health Education, 1968).

In the United States the use of mouth protectors has long been compulsory for junior teams in high-risk sports such as American football and ice hockey (Bureau of Dental Health Education, 1963). However, in most countries mouth protectors are used on a voluntary bases and are therefore uncommon. As long as they are not obligatory one can only encourage their use. As international sportsmen are, in many respects, trendsetters for recreational sportsmen it is important to determine the behaviour of this group towards mouth protectors with regard to their promotion. In considering a possible relation between the level of risk and the attitude towards mouth protectors, the aim of this survey was to gain insight into the risk factor of dental trauma for international sportsmen. Further, the extent to which they own and use mouth protectors and the factors which influence their use were investigated.

\section{MATERIALS AND METHODS}

This survey was conducted in 1984 and 1985 during three important international tournaments: the Champions' Trophy, the European Mens' Championship and the World Ladies' Championship. Fifteen countries participated and in none was the use of a mouth protector obligatory.

The data were collected by means of a questionnaire (Appendix I) which was the result of an extensive pilot study. Because one of the authors participated in the tournaments all the forms were handed over personally. Assistance was given to players who had problems with the English language. The forms were checked after they were filled in. If, in spite of this check, incomplete or incorrectlycompleted forms slipped through, they were later discarded. After we had approached 314 players data was

Address for correspondence:

J. H. A. Bolhuis

Dept. of Maxillo-Facial Prosthetics

State University of Utrecht

PO Box 2020

3500 TB Utrecht

The Netherlands obtained from 162 men from twelve countries and 117 women from nine countries, a total of 279 players.

\section{RESULTS}

\section{Accident incidence}

Of the 279 hockey players who participated in this study 174 $(62 \%)$ said they had sustained a facial injury at least once. In connection with this the majority (152) consulted a physician and/or a dentist. These data are listed in Table I.

TABLE I

Dental and facial injuries to players which necessitated professional treatment $(\mathbf{N}=\mathbf{2 7 9}) *$.

\begin{tabular}{lrcc}
\hline & \multicolumn{2}{c}{ Frequency } & $\begin{array}{c}\text { Percentage of total } \\
\text { Women }\end{array}$ \\
& $N=117$ & $N=162$ & $\begin{array}{c}\text { Men } \\
\text { number of respondents } \\
N=279\end{array}$ \\
\hline Teeth and alveolar bone & $19(16 \%)$ & $36(22 \%)$ & $20 \%$ \\
Alveolar arch & $14(12 \%)$ & $18(11 \%)$ & $12 \%$ \\
Lower jaw & $10(9 \%)$ & $12(7 \%)$ & $8 \%$ \\
Upper jaw & $5(5 \%)$ & $12(7 \%)$ & $6 \%$ \\
Other facial injuries & $36(31 \%)$ & $47(29 \%)$ & $30 \%$ \\
\hline
\end{tabular}

*Some had more than one injury

To look for possible differences between the countries the data were subdivided (Table II).

The data were rearranged to demonstrate a possible difference in dental injuries between players using a protector and those not using one (Table III).

The percentage of players who wear a mouth protector is $33 \%$. When we consider the group interviewed as a sample of the population of international top-players we can state that there is a significant difference between players who never use a protector and players who sometimes or often use one (chi-sq. $=7.12 ; \mathrm{df}=1 ; \mathrm{p} \mathrm{0.01}$ ).

\section{Owners and users of a mouth protector}

Of the players $43 \%$ said they had a mouth protector, $7 \%$ said that they had owned one at some time and $50 \%$ said they had never owned one. Of the (ex)owners $77 \%$ obtained it from a dentist and $23 \%$ bought it in a sports shop or elsewhere. Table IV shows the figures for men and women. Looking at the group as a sample of all international players there is a significant difference in the possession of a mouth protector between men and women (chi-sq. $=54.31 ; \mathrm{df}=2$; p 0.001). 
TABLE ॥

Incidence of dental and/or facial injuries among international hockey players by nationality.

\begin{tabular}{|c|c|c|c|c|c|c|c|c|c|c|c|c|c|c|}
\hline & \multicolumn{2}{|c|}{$\mathbf{N}$} & \multicolumn{2}{|c|}{ Teeth } & \multicolumn{2}{|c|}{$\begin{array}{l}\text { Upper } \\
\text { jaw }\end{array}$} & \multicolumn{2}{|c|}{$\begin{array}{l}\text { Lower } \\
\text { jaw }\end{array}$} & \multicolumn{2}{|c|}{$\begin{array}{c}\text { Alvoolar } \\
\text { arch }\end{array}$} & \multicolumn{2}{|c|}{ Others } & \multicolumn{2}{|c|}{ Total } \\
\hline & $w$ & $M$ & $w$ & $M$ & $w$ & $M$ & $w$ & $M$ & $w$ & $\mathbf{M}$ & $\mathbf{w}$ & $M$ & $w$ & $\mathbf{M}$ \\
\hline Argentina & 15 & - & 1 & - & 2 & - & 0 & - & 0 & - & 5 & - & 8 & - \\
\hline Australia & 16 & 14 & 3 & 5 & 1 & 1 & 1 & 2 & 4 & 2 & 4 & 5 & 13 & 15 \\
\hline Austria & - & 11 & - & 1 & - & 1 & - & 0 & - & 1 & - & 1 & - & 4 \\
\hline Canada & 14 & - & 1 & - & 0 & - & 3 & - & 4 & - & 9 & - & 17 & - \\
\hline England & 14 & 11 & 4 & 1 & 0 & 0 & 0 & 2 & 1 & 5 & 5 & 6 & 10 & 14 \\
\hline Holland & 12 & 16 & 3 & 4 & 0 & 2 & 0 & 0 & 1 & 1 & 2 & 6 & 6 & 13 \\
\hline India & - & 9 & - & 2 & - & 0 & - & 0 & - & 0 & - & 1 & - & 3 \\
\hline Ireland & 13 & 16 & 2 & 8 & 0 & 1 & 4 & 2 & 0 & 3 & 5 & 4 & 11 & 18 \\
\hline New Zealand & 16 & 14 & 2 & 4 & 0 & 1 & 1 & 0 & 2 & 0 & 2 & 8 & 7 & 13 \\
\hline Pakistan & - & 12 & - & 0 & - & 0 & - & 0 & - & 0 & - & 1 & - & 1 \\
\hline Poland & - & 16 & - & 3 & - & 3 & - & 3 & - & 3 & - & 0 & - & 12 \\
\hline Scotland & - & 16 & - & 3 & - & 1 & - & 1 & - & 0 & - & 3 & - & 8 \\
\hline Spain & - & 13 & - & 1 & - & 0 & - & 0 & - & 3 & - & 5 & - & 9 \\
\hline USA & 8 & - & 3 & - & 1 & - & 1 & - & 2 & - & 1 & - & 8 & - \\
\hline West Germany & 9 & 14 & 0 & 4 & 1 & 2 & 0 & 2 & 0 & 0 & 3 & 7 & 4 & 15 \\
\hline Total & 117 & 162 & 19 & 36 & 5 & 12 & 10 & 12 & 14 & 18 & 36 & 47 & 84 & 125 \\
\hline
\end{tabular}

$-=$ no participants $\quad W=$ women $\quad M=$ men

TABLE III

Use of a mouth protector* versus dental injuries $(\mathbf{N}=\mathbf{2 7 9})$.

\begin{tabular}{lllllrl}
\hline & Often & Sometimes & & Never \\
\hline No injuries & 67 & $(72 \%)$ & 4 & $(66 \%)$ & 153 & $(85 \%)$ \\
Injuries & 26 & $(28 \%)$ & 2 & $(33 \%)$ & 27 & $(15 \%)$ \\
& 93 & $(33 \%)$ & 6 & $(2 \%)$ & 180 & $(65 \%)$
\end{tabular}

*During matches

Table IVB shows these data for the different countries.

TABLE IVA

The difference in the possession of a mouth protector between men and women.

\begin{tabular}{lllllrl}
\hline & \multicolumn{1}{l}{ Yes } & \multicolumn{2}{c}{ No } & & At some time \\
\hline Women & 78 & $(67 \%)$ & 28 & $(24 \%)$ & 11 & $(9 \%)$ \\
Men & 43 & $(27 \%)$ & 111 & $(69 \%)$ & 8 & $(5 \%)$ \\
\hline
\end{tabular}

Owing a protector does not necessarily mean that it is used. Most of the owners (men $70 \%$, women $80 \%$ ) claim to usually wear a protector during matches. For training the percentages are considerably lower for men as well as women.

Table $V$ demonstrates why mouth protectors are not used; discomfort is the most common complaint. It was investigated whether there was any difference with respect to the purchase source: dentist or sports shop. It appears that men who obtained their mouth protectors from a dentist use them more frequently $(82 \%)$ than those who obtained them elsewhere $(22 \%)$. For women there was no difference in this respect $(80-82 \%)$. Among the players who obtained their protectors from a dentist the answers "disturbs my breathing" and "uncomfortable" are given less frequently than among players who obtained protectors in a sports shop or elsewhere.
TABLE IVB

The posesssion of a mouth protector in the different countries.

\begin{tabular}{lcccccccc} 
& \multicolumn{2}{c}{ N } & \multicolumn{2}{c}{ Yes } & \multicolumn{2}{c}{ No } & \multicolumn{2}{c}{ At some time } \\
& W & $M$ & W & $M$ & $W$ & $M$ & $W$ & $M$ \\
\hline Argentina & 15 & - & 3 & - & 10 & - & 2 & - \\
Australia & 16 & 14 & 15 & 12 & 0 & 2 & 1 & 0 \\
Austria & - & 11 & - & 0 & - & 11 & - & 0 \\
Canada & 14 & - & 14 & - & 0 & - & 0 & - \\
England & 14 & 11 & 7 & 7 & 7 & 2 & 0 & 2 \\
Holland & 12 & 16 & 5 & 4 & 2 & 11 & 5 & 1 \\
India & - & 9 & - & 0 & - & 9 & - & 0 \\
Ireland & 13 & 16 & 11 & 4 & 0 & 7 & 2 & 5 \\
New Zealand & 16 & 14 & 15 & 13 & 0 & 1 & 1 & 0 \\
Pakistan & - & 12 & - & 0 & - & 12 & - & 0 \\
Poland & - & 16 & - & 0 & - & 16 & - & 0 \\
Scotland & - & 16 & - & 3 & - & 13 & - & 0 \\
Spain & - & 13 & - & 0 & - & 13 & - & 0 \\
USA & 8 & - & 8 & - & 0 & - & 0 & - \\
West Germany & 9 & 14 & 0 & 0 & 9 & 14 & 0 & 0 \\
\hline Total & 117 & 162 & 78 & 43 & 28 & 111 & 11 & 8 \\
\hline
\end{tabular}

$-=$ no participants $\quad W=$ women $\quad M=$ men

TABLE V

Arguments for giving up the use of a mouth protector $(\mathrm{N}=\mathbf{8 3})$.

\begin{tabular}{lcc}
\hline Reasons & No. of crosses* & Percentage \\
\hline Uncomfortable & 54 & $65 \%$ \\
Caused nausea & 12 & $15 \%$ \\
Interfered with breathing & 2 & $3 \%$ \\
Other reasons & 23 & $28 \%$ \\
\hline
\end{tabular}

* More than one alternative could be indicated.

Between the countries there is a great difference in the use of the mouth protector. Table VI shows these data. 
TABLE VI

The use of mouth protectors for the different countries.

\begin{tabular}{|c|c|c|c|c|c|c|}
\hline & \multicolumn{2}{|c|}{$\mathbf{N}$} & \multicolumn{2}{|c|}{ During matches } & \multicolumn{2}{|c|}{ During training } \\
\hline & $w$ & $\mathbf{M}$ & $\mathbf{w}$ & M & $\mathbf{w}$ & $\mathbf{M}$ \\
\hline Argentina & 3 & - & $33 \%$ & - & $0 \%$ & - \\
\hline Australia & 15 & 12 & $94 \%$ & $100 \%$ & $27 \%$ & $83 \%$ \\
\hline Canada & 14 & - & $100 \%$ & - & $79 \%$ & - \\
\hline England & 7 & 7 & $71 \%$ & $29 \%$ & $43 \%$ & $0 \%$ \\
\hline Holland & 5 & 4 & $80 \%$ & $50 \%$ & $40 \%$ & $25 \%$ \\
\hline Ireland & 11 & 4 & $46 \%$ & $50 \%$ & $27 \%$ & $50 \%$ \\
\hline New Zealand & 15 & 13 & $80 \%$ & $92 \%$ & $53 \%$ & $54 \%$ \\
\hline Scotland & - & 3 & - & $0 \%$ & - & $0 \%$ \\
\hline USA & 8 & - & $100 \%$ & - & $75 \%$ & 一 \\
\hline
\end{tabular}

Only $20 \%$ of the total group ( $N=279$ ) claim to wear a protector both during matches and training.

\section{Reasons why a mouth protector is not purchased}

Table VII shows the replies to the question why players had not purchased a mouth protector.

TABLE VII

Why players did not purchase a mouth protector $(N=139)$.

\begin{tabular}{lcc}
\hline Reasons & Number* & Percentage \\
\hline Don't find it necessary & 77 & $55 \%$ \\
Appears uncomfortable & 43 & $31 \%$ \\
Too expensive & 8 & $5 \%$ \\
Looks ugly & 5 & $4 \%$ \\
Not obtainable & 20 & $14 \%$ \\
\hline
\end{tabular}

* More than one alternative could be indicated.

"Don't find it necessary" is by far the most frequent argument, followed by "appears uncomfortable". The answer "a mouth protector is not obtainable" was given by 16 players from Poland.

\section{DISCUSSION}

From this survey it appears that from our group of international hockey players, $62 \%$ had sustained a facial injury at least once. The real percentages will be even higher because firstly, our estimate refers only to those players who are still active. It can be assumed that some players who sustained serious injuries on the hockey field have stopped playing. Secondly we asked the players whether they had had a dental injury "once". It appeared that some players had sustained a dental trauma twice or even three times.

A survey in Holland among 3,577 recreational players (all players in the two top leagues were excluded) showed $32 \%$ facial injuries (Bolhuis et al, 1986). This percentage is significantly lower than the figures for the international players (32\% compared with $62 \%)$. Possibly this difference is caused by the fanatical attitude of the international players who are consciously or subconsciously prepared to take more risks, and because the "exposure time" of the international players is relatively high. Although one would expect to find the lowest number of dental traumas among the conscientious wearers of mouth protectors, this survey revealed the opposite result. We found a significantly greater incidence in this group. Since we did not ask whether these injuries occurred before or after the purchase of a protector, no conclusions can be drawn. In the above mentioned survey in Holland we found that $96 \%$ of the injured players had bought the mouth protector after an accident. It seems likely that the same applies to this group of international players.

Of the international players $50 \%$ had purchased a mouth protector at some time. This may be the result of frequent stimulation via club dentists, dental hygienists and dental technicians who play hockey themselves and articles in sport bulletins and magazines. Nevertheless, $50 \%$ do not buy a mouth protector. The main reason given is that it is unnecessary. With an accident rate of $20 \%$ in this group this argument is hardly credible. It is, however, not the possession of a protector, but the wearing of it that is important. From this point of view the picture is considerably less encouraging. Less than a quarter of the international players in this survey use a mouth protector consistently during matches and training. For the recreational hockey player, in this respect, most of the international players are not the useful shining examples we had hoped for.

\section{APPENDIX}

NAME MAN / WOMAN

AGE

(Please put a cross by the relevant answer. Questions that are not relevant should be left open.)

1. How long have you played club hockey? years

2. A) Have you ever had a mouth protector?

$\square$ yes

$\square$ no $\square$ yes but no longer

B) Was the mouth protector made by a dentist?

yes

$\square$ no

3. If you no longer have a mouth protector but have had one is this because

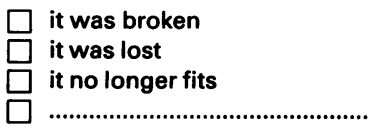

4. If you have never had a mouth protector what are the reason(s)?

$\square$ too expensive
$\square$ appeared unnecessary
$\square$ appeared ugly
$\square$ seemed to be uncomfortable
to wear

5. A) If you have a mouth protector do you wear it — during matches

mostly - during training sometimes (almost) never mostly sometimes (almost) never

B. If question 5A was answered with "(almost) never" or "sometimes" is this because the mouth protector

interfers with breathing is uncomfortable causes nausea

6. A) Have you ever sustained an injury $\square$ yes to your face during a hockey match?

If yes, did you need to consult a doctor/dentist/oral surgeon/

$\square$ yes hospital?

C) Did the injury affect your

$\square$ front or back teeth
$\square$ upper jaw
$\square$ lower jaw
$\square$ cheek bone




\section{References}

Bolhuis, J. H. A., Baarda, D. B., Leurs, J. M. M. and Flögel, G. E., 1986 "Incidentie en preventie van tandtraumata bij de hockeysport". Ned. Tijdschr.Tandheelkd. 93: 283-7.

Garon, W. M., Merkle, A. and Wright, J. T., 1986 "Mouthprotectors and oral trauma: a study of adolescent football players". J.Amer.Dent.Ass. 112: 663-5.
Bureau of Health Education, 1984 "Mouth protectors and sportsteam dentist". J.Amer.Dent.Ass. 109: 84-7.

Bureau of Dental Health Education, 1986 "Mouth protectors: a progress report". J.Amer.Dent.Ass. 77: 632-6.

Wijn, J. R. de, Vrijhoef, M. M. A. and Linn, E. W., 1986 "De werking en effectieviteit van mondbeschermers". Ned.Tijdschr.Tandheelkd. 93: 112.

Bureau of Dental Health Education, 1963 "Mouth protectors: 1962 and the future". J.Amer.Dent.Ass. 66: 539-43.

\section{BOOK REVIEW}

Title:

Authors:

Publisher:

\section{A COLOUR ATLAS OF SURFACE ANATOMY}

Kenneth M. Backhouse and Ralph T. Hutchings

Wolfe Medical Publications, London 1986

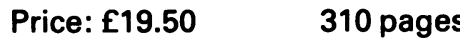

490 Coloured photos

Index

ISBN 0723408017

The authors had in mind the needs of not only doctors and dentists but also those in professions supplementary to medicine, physical education and art. The combination of an experienced anatomist (Reader at the Royal College of Surgeons) and a first class medical photographer has produced one of the best colour atlases Wolfe have published. Great credit must also go to the models who must have spent many long, cold and often embarrassing hours during photographic sessions.

Having been a colleague of Ken Backhouse in Newcastle some 35 years ago, I can see how his many interests have had a large influence on the book. His early interest in plastic surgery is obvious from the first few pages and his detailed pictures of the movements of the hand reflects the self insertion of needle electrodes into the lumbrical and interosseous muscles of his own hands for electromyographic studies. Photographs of the chest are superimposed on photographs of the bronchial tree taken from coloured resin casts and of the lungs injected with coloured gelatin (and again I have memories of helping Ken with some of these and having to hide semi-decomposing lungs from pigs, seals and monkeys from the eyes of passers-by).

Other photographs have the blood and lymph vessels and nerves superimposed and techniques of manual palpation and of local anaesthetic injection clearly illustrated. My main disappointment was a lack of photographs of the body in vigorous action, as Ken when teaching anatomy to physical education students used a lively and practical approach to the actions of the body in athletics, gymnastics and ballet. This should prove a most valuable book to students of medicine, dentistry, physiotherapy, physical education and art. The photographs are excellent and the descriptive text both detailed and easily understood. Very good value for under twenty pounds.

Henry E. Robson

\section{BOOK REVIEW}

Title:

\section{MANUEL PRATIQUE DE MÉDECINE DU SPORT}

Author: $\quad$ P. Pilardeau (in French)

Publisher: $\quad$ Masson Editeur, Paris 1987

$\begin{array}{lllll}\text { Price: } 150 \text { Fr. F. } 200 \text { pages } \quad 60 \text { figs. Index Soft cover } & \text { ISBN } 2225810338\end{array}$

This book is designed for medical students, general practitioners and students entering diploma courses in Sports Medicine.

In France, specific training for doctors in Sports Medicine leading to a Diploma enabling a general practitioner to achieve specialist status is well established. There is a well developed principle of examination of the athlete for aptitutde and fitness for a sport which creates a special need for this discipline.

M. Pilardeau's book sets out to prepare the student on a very broad base. He begins with chapters on normal physiology with detailed examination of the effects of exercise.

A section is then dedicated to the aptitude assessment as used in France and the regulations thereto, especially those conditions contra-indicating various activities activities and aims of particular training.

M. Pilardeau then considers the relationships between medical conditions such as allergy and cardiac problems and physical exercise, both from the point of view of risks and benefits.

Sections are next devoted to consideration of youth, growth, age, physical - mental handicap, hormonal effects and so on.

Finally the traumatology of sport and appropriate treatment methods are dealt with systematically, if rather briefly.

I feel this book is useful for the market at which it is aimed, i.e. the French medical student or coach/trainer who needs a wide introduction to the whole field of sport and medicine. Those needing more detailed advice regarding management of injuries may however be disappointed. 